EGU21-11097

https://doi.org/10.5194/egusphere-egu21-11097

EGU General Assembly 2021

(c) Author(s) 2021. This work is distributed under

the Creative Commons Attribution 4.0 License.

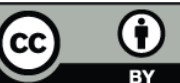

\title{
Contrasting seasonal changes in temperature, precipitation and snow cover simulated over the European Alps during the twentieth century
}

Martin Ménégoz ${ }^{1}$, Julien Beaumet ${ }^{1}$, Hubert Gallée ${ }^{1}$, Xavier Fettweis ${ }^{2}$, Samuel Morin ${ }^{3}$, Juliette Blanchet ${ }^{1}$, Delphine Six ${ }^{1}$, Christian Vincent ${ }^{1}$, Nicolas C. Jourdain ${ }^{1}$, Bruno Wilhelm ${ }^{1}$, and Sandrine Anquetin

1'Univ. Grenoble Alpes, CNRS, IRD, G-INP, IGE, 38000 Grenoble, France (martin.menegoz@univ-grenoble-alpes.fr)

${ }^{2}$ F. R. S. - FNRS, Laboratory of Climatology, Department of Geography, University of Liège, 4000 Liège, Belgium

${ }^{3}$ Univ. Grenoble Alpes, Université de Toulouse, Météo-France, CNRS, CNRM, Centre d'Études de la Neige, 38000 Grenoble,

France

The evolution of temperature, precipitation and snow cover in the European Alps have been simulated with the regional climate model MAR applied with a 7 kilometre horizontal resolution and driven by the ERA-20C (1902-2010) and the ERA5 reanalyses (1981-2018). A comparison with observational datasets, including French and Swiss local meteorological stations, in-situ glacier mass balance measurements and reanalysis product demonstrates high model skill for snow cover duration and snow water equivalent (SWE) as well as for the climatology and the interannual variability of both temperature and precipitation. The relatively high resolution allows to estimate the meteorological variables up to $3000 \mathrm{~m}$.a.s.l. The vertical gradient of precipitation simulated by MAR over the European Alps reaches 33\% km-1 (1.21 mmd-1.km-1) in summer and $38 \% \mathrm{~km}-1$ (1.15mmd mmd-1.km-1) in winter, on average over 1971-2008 and shows a large spatial variability. This study evidences seasonal and altitudinal contrasts of climate trends over the Alps. A significant (pvalue $<0.05$ ) increase in mean winter precipitation is simulated in the northwestern Alps over $1903-2010$, with changes typically reaching $20 \%$ to $40 \%$ per century, a signal strongly modulated by multi-decadal variability during the second part of the century. A general drying is found in summer over the same period, exceeding $20 \%$ to $30 \%$ per century in the western plains and $40 \%$ to $50 \%$ per century in the southern plains surrounding the Alps but remaining smaller $(<10 \%)$ and not significant above 1500 ma.s.l. Over 1903-2010, the maximum of daily precipitation (Rx1day) shows a general and significant increase at the annual timescale and also during the four seasons, reaching local values between $20 \%$ and $40 \%$ per century over large parts of the Alps and the Apennines. Trends of Rx1day are significant (pvalue $<0.05$ ) only when considering long time series, typically 50 to 80 years depending on the area considered. Some of these trends are nonetheless significant when computed over 1970-2010, suggesting a recent acceleration of the increase in extreme precipitation. Rx1day increase occurs where the annual correlation between temperature and intense precipitation is high. The highest warming rates in MAR are found at low elevations (< $1000 \mathrm{~m}$ a.s.l) in winter, whereas they are found at high elevations (> $2000 \mathrm{~m}$ a.s.l) in summer. In spring, warming trends show a maximum at intermediate elevations (1500 m to 1800 
m). Our results suggest that higher warming at these elevations is mostly linked with the snowalbedo feedback in spring and summer. 